ARTICLE

DOI: $10.1038 / s 41467-018-04433-z$

\title{
Light-induced formation of partially reduced oxygen species limits the lifetime of photosystem 1-based biocathodes
}

Fangyuan Zhao ${ }^{1}$, Steffen Hardt², Volker Hartmann ${ }^{3}$, Huijie Zhang ${ }^{2}$, Marc M. Nowaczyk (10 ${ }^{3}$, Matthias Rögner ${ }^{3}$, Nicolas Plumeré (i) ${ }^{2}$, Wolfgang Schuhmann (1) ${ }^{1}$ \& Felipe Conzuelo (i) ${ }^{1}$

Interfacing photosynthetic proteins specifically photosystem 1 (PS1) with electrodes enables light-induced charge separation processes for powering semiartificial photobiodevices with, however, limited long-term stability. Here, we present the in-depth evaluation of a PS1/Oscomplex-modified redox polymer-based biocathode by means of scanning photoelectrochemical microscopy. Focalized local illumination of the bioelectrode and concomitant collection of $\mathrm{H}_{2} \mathrm{O}_{2}$ at the closely positioned microelectrode provide evidence for the formation of partially reduced oxygen species under light conditions. Long-term evaluation of the photocathode at different $\mathrm{O}_{2}$ concentrations as well as after incorporating catalase and superoxide dismutase reveals the particularly challenging issue of avoiding the generation of reactive species. Moreover, the evaluation of films prepared with inactivated PS1 and free chlorophyll points out additional possible pathways for the generation of oxygen radicals. To avoid degradation of PS1 during illumination and hence to enhance the long-term stability, the operation of biophotocathodes under anaerobic conditions is indispensable.

\footnotetext{
${ }^{1}$ Analytical Chemistry - Center for Electrochemical Sciences (CES), Ruhr-Universität Bochum, Universitätsstr. 150, Bochum 44780, Germany. ${ }^{2}$ Center for Electrochemical Sciences - Molecular Nanostructures, Ruhr-Universität Bochum, Universitätsstr. 150, Bochum 44780, Germany. ${ }^{3}$ Plant Biochemistry, RuhrUniversität Bochum, Universitätsstr. 150, 44780 Bochum, Germany. Correspondence and requests for materials should be addressed to W.S. (email: wolfgang.schuhmann@rub.de) or to F.C. (email: felipe.conzuelo@rub.de)
} 
T he integration of isolated photosynthetic protein complexes such as photosystem 1 (PS1) or photosystem 2 (PS2) into semiartificial photoelectrochemical devices requires immobilization strategies that allow optimized electron transfer while ensuring its adequate stability. The design-engineered electron-transfer chains for an efficient coupling of photosynthetic proteins to electrode surfaces were demonstrated for $\mathrm{PS}^{1-10}$, PS2 $2^{11-15}$, and bacterial reaction centers ${ }^{16}, 17$. However, light-induced damage of photosynthetic protein complexes in semiartificial assemblies causes fast degradation together with a drop in activity. Consequently, the potential applicability of biohybrid devices is considerably limited ${ }^{18,19}$.

Environmental as well as light-induced stress in plants creates an imbalance between the produced reactive oxygen species (ROS) and scavenging antioxidant systems ${ }^{20}$. PS2 has been considered the primary target for photoinhibition ${ }^{21}$ and much is known about the mechanism of damage and repair in vivo ${ }^{21-26}$. In contrast, PS1 presents a considerably longer life time in vivo ${ }^{27}$ and has been considered to be less sensitive to light stress than $\mathrm{PS}^{22,28}$. However, PS1 is similarly susceptible to environmental stress $^{29}, 30$, with ROS causing inactivation of the protein complex $22,23,31,32$. Moreover, since damaged PS1 is not repaired as PS2 ${ }^{33}$, PS1 damage seems to be irreversible and may have a much stronger impact on the survival of plants than PS2 photoinhibition ${ }^{23}$.

In photobioelectrochemical devices that utilize $\mathrm{O}_{2}$ as terminal electron acceptor, the generation of ROS is inherently associated. Since the reduction of $\mathrm{O}_{2}$ to $\mathrm{H}_{2} \mathrm{O}$ requires four electrons, the stepwise production of partially reduced intermediates prevails. The initial step in the formation of partially reduced oxygen species is the generation of the superoxide radical $\left(\mathrm{O}_{2}{ }^{-}\right)$by a one electron reduction of molecular oxygen. The cascade of reactions continues with dismutation of $\mathrm{O}_{2}{ }^{-}$leading to the production of $\mathrm{H}_{2} \mathrm{O}_{2}$ and the formation of the hydroxyl radical ( $\mathrm{HO}^{*}$ ) by a one electron reduction process ${ }^{20,25,34}$. Moreover, a kinetically hindered uptake of electrons from the $\mathrm{F}_{\mathrm{B}}{ }^{-}$site of PS1 can result in back-reactions leading to the formation of chlorophyll in an excited triplet state, able to react with $\mathrm{O}_{2}$ under formation of singlet oxygen, $\mathrm{O}_{2}\left({ }^{1} \Delta_{\mathrm{g}}\right)^{35}$. All these highly reactive species can easily disrupt any biological assembly 36,37 .

Many PS1-based semiartificial devices make use of redox mediators to enhance the electron-transfer rate from the photosynthetic protein complex to $\mathrm{O}_{2}$. Viologen derivatives exhibit sufficiently negative redox potentials and are widely used as redox mediators for the efficient electrocatalytic reduction of $\mathrm{O}_{2}{ }^{38,39}$. However, the increased electron-transfer rates are also associated with an increased generation of partially reduced oxygen species. Particularly, methyl viologen $\left(\mathrm{MV}^{2+}\right)$ is known for its herbicidal activity in plants due to the production of partially reduced ROS, with $\mathrm{H}_{2} \mathrm{O}_{2}$ as the major product in aqueous solutions, and peroxidation of lipid constituents eventually leading to necrosis ${ }^{3}{ }^{2}$. $\mathrm{MV}^{2+}$ effectively scavenges the high-energy electrons from PS1. A voltammetric study about $\mathrm{MV}^{2+}$-mediated reduction of $\mathrm{O}_{2}$ suggested ${ }^{39,40}$ that the generated methyl viologen radical cation $\left(\mathrm{MV}^{+\bullet}\right)$ reacts efficiently with $\mathrm{O}_{2}$ to generate the superoxide radical (Eq. (1)):

$$
\mathrm{MV}^{+\bullet}+\mathrm{O}_{2} \rightarrow \mathrm{MV}^{2+}+\mathrm{O}_{2}^{--} \quad k_{\mathrm{f}}=6 \times 10^{9} \mathrm{M}^{-1} \mathrm{~s}^{-1}
$$

Subsequently, the generated $\mathrm{O}_{2}^{--}$may dismutate or further react with $\mathrm{MV}^{+\bullet}$ with the eventual generation of $\mathrm{H}_{2} \mathrm{O}_{2}$ (Eqs. (2) and (3)):

$$
\begin{gathered}
2 \mathrm{O}_{2}^{\bullet-}+2 \mathrm{H}^{+} \rightarrow \mathrm{O}_{2}+\mathrm{H}_{2} \mathrm{O}_{2} \quad k_{\mathrm{f}}=1.3 \times 10^{6} \mathrm{M}^{-1} \mathrm{~s}^{-1} \\
\mathrm{MV}^{+\bullet}+\mathrm{O}_{2}^{\bullet-}+2 \mathrm{H}^{+} \rightarrow \mathrm{MV}^{2+}+\mathrm{H}_{2} \mathrm{O}_{2} \quad k_{\mathrm{f}}=6.5 \times 10^{8} \mathrm{M}^{-1} \mathrm{~s}^{-1}
\end{gathered}
$$

Therefore, the occurrence of $\mathrm{H}_{2} \mathrm{O}_{2}$ can be considered as evidence for the generation of partially reduced oxygen species causing deleterious processes of PS1-based biophotocathodes under aerobic conditions. Our aim was to implement an analytical system for the simultaneous evaluation of $\mathrm{O}_{2}$ consumption and associated $\mathrm{H}_{2} \mathrm{O}_{2}$ production under irradiation and to gain deeper understanding on light-induced stress.

As the integration of isolated photosynthetic protein complexes with electrodes decreases their stability and prevents biological repair mechanisms, the effect of reactive species for semiartificial devices is even more delicate. While competing charge transfer pathways and short circuits at the integrated chlorophyll molecules constituting antenna complexes further restrain the efficiency of PS2-based biodevices ${ }^{41}, 42$, the immobilization of isolated PS1 at electrodes has shown as well a rather limited stability upon light irradiation ${ }^{18,19,29}$. However, the long-term stability of PS1-based photoelectrodes has been commonly underestimated and much less is known about inactivation processes and ROS generation at devices using isolated PS1 coupled to electrode surfaces. Particularly, under aerobic conditions and when $\mathrm{MV}^{2+}$ is used as an electron acceptor, the fast electron transfer to $\mathrm{O}_{2}$ is unequivocally causing the generation of partially reduced oxygen species ${ }^{39}$, leading to an eventual loss in PS1 activity. The deleterious effect of partially reduced oxygen species generated under light is therefore also of particular importance for PS1-based photobioelectrodes operated under aerobic conditions, an effect which until now has been suggested but not extensively evaluated because of the lack of experimental evidence.

Scanning electrochemical microscopy (SECM) is a scanning probe technique for the visualization of local electrochemical activity. An accurately positioned microelectrode tip is used as a probe for the evaluation of electrochemical processes or collection of species of interest evolved at the sample. Particularly for the analysis of photoactive materials, scanning photoelectrochemical microscopy (SPECM) was suggested combining SECM with a light source for the controlled and focalized illumination of the sample $^{43,44}$.

We present an in-depth evaluation of a highly efficient photobiocathode ${ }^{18}$ comprising isolated PS1 embedded within an Oscomplex-modified polymer. SPECM is used for investigation of light-induced stress at the PS1-based photocathode and the concomitant generation of partially reduced oxygen species supposedly involved in PS1 degradation. Evidence for the formation of partially reduced oxygen species under illumination of PS1/ redox polymer-modified photobiocathodes is demonstrated by in situ collection of $\mathrm{H}_{2} \mathrm{O}_{2}$ at the SPECM tip. Simultaneous localized irradiation of the PS1-based photocathode and collection of $\mathrm{H}_{2} \mathrm{O}_{2}$ at different $\mathrm{O}_{2}$ concentrations and in the presence of scavenging enzymes, i.e., catalase (Cat) and superoxide dismutase (SOD), is presented. Moreover, by studying inactivated PS1 and free chlorophyll immobilized within the Os-complex-modified polymer, previous observations at PS2-based bioanodes concerning the light-induced generation of partially reduced oxygen intermediates at chlorophyll pigments were confirmed ${ }^{41,42}$.

\section{Results}

Electron transfer in PS1/Os-P with $\mathrm{O}_{2}$ as terminal acceptor. By integration of isolated PS1 within an optimized redox hydrogel and working under experimental conditions that ensure that the process is limited only by the availability of $\mathrm{O}_{2}$ as terminal electron acceptor, benchmark electron-transfer rates were achieved that are even capable of outperforming the rates observed in natural photosynthesis ${ }^{18}$. For the evaluation of the formation of partially reduced oxygen species and protein 
stability in semiartificial devices, we selected this very same PS1based photocathode that has been previously optimized in terms of electronic communication with the electrode surface (Fig. 1a).

a

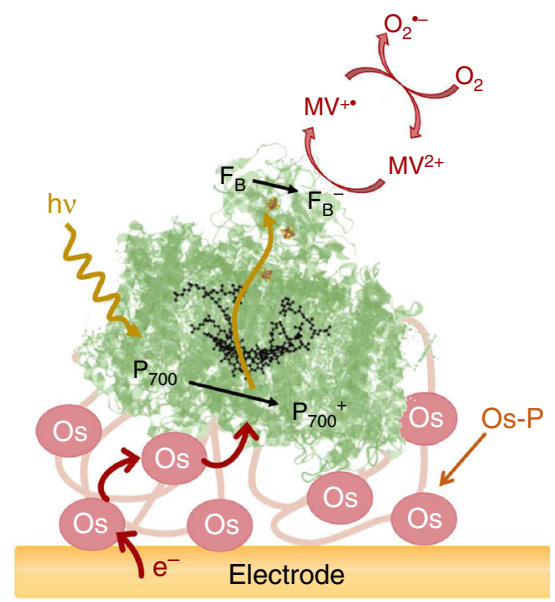

b

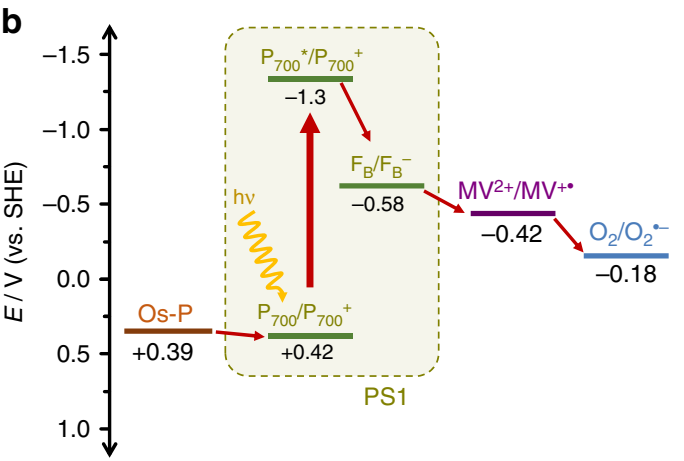

Fig. 1 Overview of the charge transfer pathway in the PS1/Os-complexmodified redox polymer-based photocathode. a Schematic representation of the PS1 photocathode. The redox polymer acts simultaneously as immobilization matrix and as a mediator for the reduction of the photooxidized $\mathrm{P}_{700}{ }^{+}$site at PS1. $\mathrm{MV}^{2+}$ is used as electron scavenger in solution for the uptake of electrons from the reduced Fe-S cluster $\mathrm{F}_{\mathrm{B}}{ }^{-}$at the stromal side of PS1. The efficient reduction of $\mathrm{O}_{2}$ in solution by the generated $\mathrm{MV}^{+}{ }^{\cdot}$ allows fast regeneration of $\mathrm{MV}^{2+}$ in solution with the concomitant generation of superoxide radicals. $\left(\mathrm{P}_{700}{ }^{\star}\right.$ : photo-excited $\mathrm{P}_{700}$ special chlorophyll pair). b Energy levels for the terminal cofactors involved in the electron-transfer sequence of PS1 and formal potentials of the Os-complex-modified polymer (Os-P), methyl viologen, and the $\mathrm{O}_{2} / \mathrm{O}_{2}{ }^{\circ}-$ couple at $\mathrm{pH} 7.0\left(25^{\circ} \mathrm{C}\right)$
The selected biodevice is a highly efficient assembly of PS1 integrated within an Os-complex-modified redox polymer acting as an immobilization matrix and as redox mediator for the transfer of electrons from the electrode surface to the PS1 moieties. As illustrated in the corresponding energy level diagram in Fig. 1b, PS1 performs charge separation upon light absorption, and after internal electron transfer, a final long-lived state with a charge recombination lifetime of about $20 \mathrm{~ms}$ is obtained ${ }^{3}$. In this state, the two opposite redox sites at PS1 are the photooxidized special chlorophyll pair $\mathrm{P}_{700}{ }^{+}$at the luminal side and the reduced terminal $\mathrm{Fe}-\mathrm{S}$ cluster $\mathrm{F}_{\mathrm{B}}{ }^{-}$at the stromal side. The Os-complexes in the redox hydrogel donate electrons for the reduction of $\mathrm{P}_{700}{ }^{+}$, while the high-energy electron is scavenged by the redox mediator $\mathrm{MV}^{2+}$ followed by the reduction of $\mathrm{O}_{2}$ as terminal electron acceptor. The fast process of $\mathrm{O}_{2}$ reduction by the generated $\mathrm{MV}^{+} \cdot$ allows, on the one hand, a fast regeneration of the redox mediator in solution for the efficient uptake of electrons from the $\mathrm{F}_{\mathrm{B}}{ }^{-}$site, thus ensuring high photocurrents. However, on the other hand, superoxide radicals are simultaneously generated, which can also react with $\mathrm{MV}^{+}$or dismutate, leading to the eventual generation of $\mathrm{H}_{2} \mathrm{O}_{2}$. This electrochemical pathway leads to the generation of partially reduced ROS in the surroundings of the immobilized protein complexes and may have a deleterious effect leading to the possible inactivation of PS1 under illumination.

SPECM evaluation of produced $\mathrm{H}_{2} \mathrm{O}_{2}$ at the PS1 photocathode. A dual Pt microdisk electrode was used as electrochemical probe in an SPECM setup, allowing multiple parameters to be simultaneously monitored in a localized space. As depicted in Fig. 2, the SPECM setup allowed to monitor the photocurrent from the sample electrode, using the glass sheath of the dual microelectrode tip as extended light guide for the localized and controlled irradiation of the PS1 photocathode. Simultaneously, $\mathrm{O}_{2}$ consumption was monitored by detecting the $\mathrm{O}_{2}$ reduction current at one of the $\mathrm{Pt}$ microdisk electrodes, while in parallel the oxidation of $\mathrm{H}_{2} \mathrm{O}_{2}$ was measured at the second $\mathrm{Pt}$ microdisk electrode allowing to collect $\mathrm{H}_{2} \mathrm{O}_{2}$ generated at the sample. The dual microdisk electrodes were fabricated to minimize any potential crosstalk interference between the two disk electrodes (see Supplementary Fig. 1 and Methods section). The fast electrocatalytic conversion of the products at the selected applied potentials ensures diffusion-limited processes. Moreover, the tip-to-sample distance (typically $10 \mu \mathrm{m}$ ) was kept below one tip radius $(\mathrm{Pt}$ microdisk, $a \approx 12.5 \mu \mathrm{m}$ ) for the fast and efficient collection of evolved $\mathrm{H}_{2} \mathrm{O}_{2}$.

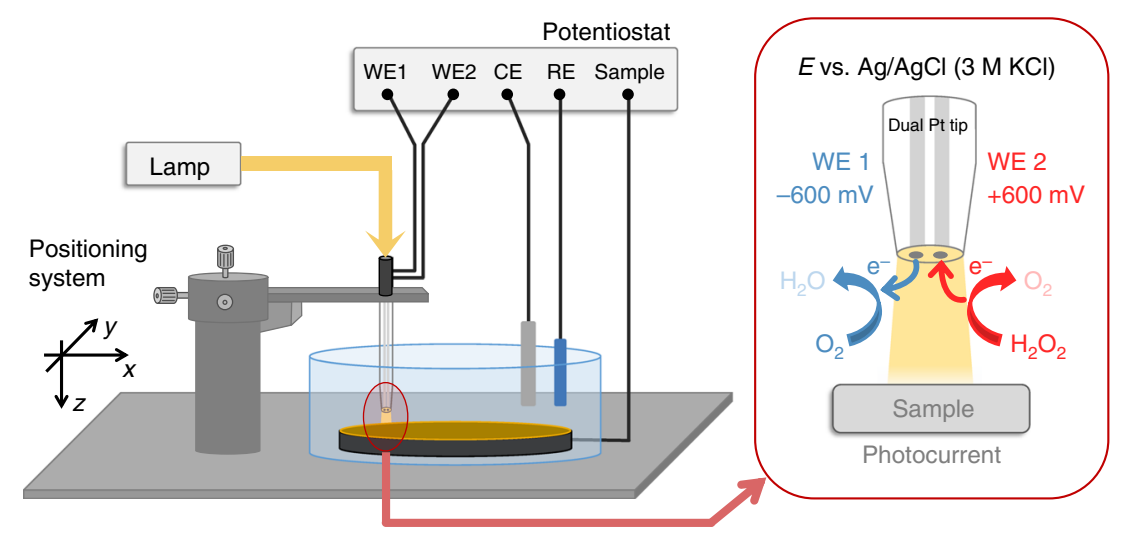

Fig. 2 The PS1/redox polymer-based photocathode is investigated using SPECM. Representation of the SPECM setup. CE: counter electrode, RE: reference electrode, WE: working electrode. Right: dual Pt microdisk tip for the simultaneous collection of $\mathrm{O}_{2}$ and $\mathrm{H}_{2} \mathrm{O}_{2}$ while allowing localized irradiation of the sample through the glass sheath of the positioned dual microelectrode tip 

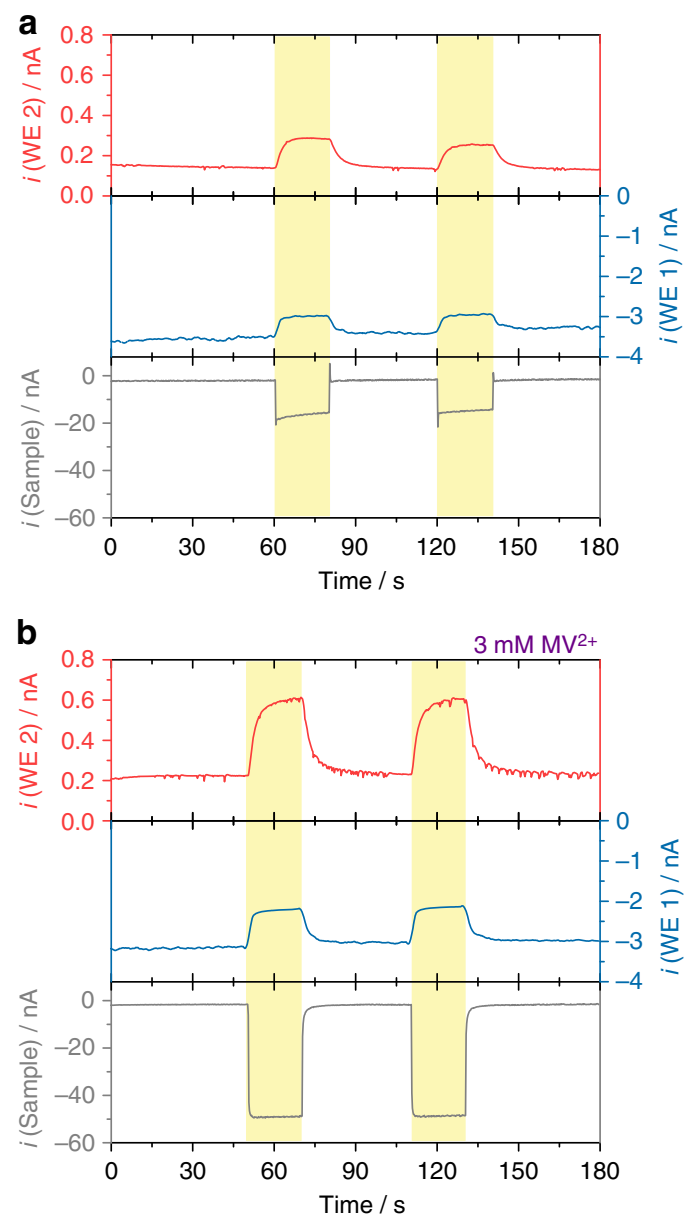

C

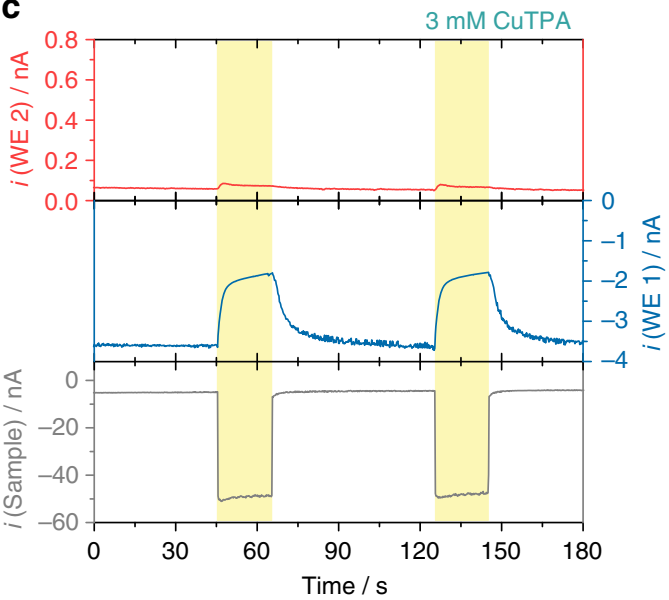

Fig. 3 Evidence for the generation of partially reduced oxygen species under irradiation. Simultaneous photochronoamperometric responses recorded during evaluation of a PS1/Os-complex-modified redox polymer photocathode on a gold electrode surface (sample) using a dual Pt microelectrode tip: a air-equilibrated buffer, $\mathbf{b}$ in the presence of $3 \mathrm{mM} \mathrm{MV}^{2}$ ${ }^{+}, \mathbf{c}$ in the presence of $3 \mathrm{mM}$ CuTPA. The sample was polarized at $0 \mathrm{mV}$ while the Pt disk microelectrodes were polarized at $-600 \mathrm{mV}(\mathrm{WE} 1)$ and $+600 \mathrm{mV}$ (WE 2) vs. $\mathrm{Ag} / \mathrm{AgCl} / 3 \mathrm{M} \mathrm{KCl}$. Electrolyte: $0.2 \mathrm{M}$ citratephosphate buffer, $\mathrm{pH}$ 7.0. Tip-to-sample distance: $10 \mu \mathrm{m}$. The sample was locally irradiated (white light, $280 \mathrm{~mW} \mathrm{~cm}^{-2}$ ) for periods of $20 \mathrm{~s}$ through the glass sheath of the positioned dual Pt microdisk electrode, as indicated by the yellow shaded regions in the graphs
Partially reduced oxygen species generated under light. The PS1-based photocathode was investigated using SPECM by performing photochronoamperometric measurements in ambient air-equilibrated solutions and working at an incident illumination intensity that ensures light saturation of the immobilized $\mathrm{PS}^{18,45}$. First, the PS1/Os-complex-modified redox polymer was analyzed in the absence of any redox mediator in solution using dissolved $\mathrm{O}_{2}$ as electron acceptor. The obtained results for the simultaneous measurement of sample photocurrent together with the $\mathrm{O}_{2}$ and $\mathrm{H}_{2} \mathrm{O}_{2}$ collection at the dual Pt microdisk electrode are summarized in Fig. 3a. The photocurrent response obtained at the sample (Fig. 3a, gray trace) exhibited an increased cathodic current upon irradiation due to the reduction of the photooxidized $\mathrm{P}_{700}{ }^{+}$site of PS1 by the Os-complexes in the redox hydrogel. Owing to the highly negative formal potential of the terminal Fe-S cluster of PS1, $\mathrm{O}_{2}$ can be directly reduced by $\mathrm{F}_{\mathrm{B}}{ }^{-}$ although with slow reaction kinetics ${ }^{45}$. In parallel, the current at the Pt microdisk for $\mathrm{O}_{2}$ collection (Fig. 3a, blue trace) shows an initial cathodic background current in the dark, corresponding with the steady-state reduction of $\mathrm{O}_{2}$ initially present in solution at the Pt microdisk electrode. Upon irradiation, a decrease in the recorded cathodic current indicates the consumption of $\mathrm{O}_{2}$ confirming the reduction of $\mathrm{O}_{2}$ by PS1. Furthermore, at the Pt microdisk electrode used for the collection of $\mathrm{H}_{2} \mathrm{O}_{2}$ (Fig. 3a, red trace), an increased anodic current was recorded upon irradiation of the sample, thus unequivocally confirming the generation of $\mathrm{H}_{2} \mathrm{O}_{2}$. It is important to note that at the applied potential for $\mathrm{O}_{2}$ collection (WE $1, E_{\text {app }}=-600 \mathrm{mV}$ vs. $\mathrm{Ag} / \mathrm{AgCl} / 3 \mathrm{M} \mathrm{KCl}$ ) partial reduction of $\mathrm{H}_{2} \mathrm{O}_{2}$ at the $\mathrm{Pt}$ surface is also possible. Therefore, the obtained net current at this electrode is a sum of the reduction of both $\mathrm{O}_{2}$ and $\mathrm{H}_{2} \mathrm{O}_{2}$.

The photocathode was then evaluated in the presence of $\mathrm{MV}^{2+}$ (Fig. 3b). As a result of the more efficient uptake of the high energy electrons from PS1 by $\mathrm{MV}^{2+}$, an increased photocurrent was now observed (Fig. 3b, gray trace). As expected, the associated current for the collection of $\mathrm{O}_{2}$ presented a similar initial background value under dark conditions but a more remarkable decrease was observed upon irradiation (Fig. 3b, blue trace). Moreover, the faster reaction kinetics in the presence of $\mathrm{MV}^{2+}$ as primary electron acceptor led to an enhanced production of partially reduced oxygen species, concomitantly with larger anodic currents for the collection of $\mathrm{H}_{2} \mathrm{O}_{2}$ at the corresponding $\mathrm{Pt}$ microelectrode (Fig. 3b, red trace). The obtained results clearly provide experimental evidence about the generation of partially reduced ROS at the PS1 photocathode by the in situ collection of $\mathrm{H}_{2} \mathrm{O}_{2}$. The collection of $\mathrm{H}_{2} \mathrm{O}_{2}$ was directly associated with the irradiation of the sample, indicating that reduced oxygen species are exclusively generated under light conditions (Fig. 3a, b). Moreover, the release of $\mathrm{H}_{2} \mathrm{O}_{2}$ was related to the consumption of $\mathrm{O}_{2}$ in the gap between the dual microelectrode tip and the sample, confirming that $\mathrm{O}_{2}$ in solution is the source of partially reduced oxygen species.

CuTPA as catalyst for the direct reduction of $\mathrm{O}_{2}$ to $\mathrm{H}_{2} \mathrm{O}$. To verify our observations, we performed a control experiment replacing $\mathrm{MV}^{2+}$ by a $\mathrm{Cu}$ complex that is able to act as catalyst for the $4 \mathrm{e}^{-}$reduction of $\mathrm{O}_{2}$ to $\mathrm{H}_{2} \mathrm{O}$, thus preventing any formation of $\mathrm{H}_{2} \mathrm{O}_{2}$. The selected complex, Cu-tris(2-pyridylmethyl)amine nitrate (CuTPA), has been described before as an effective catalyst for the direct reduction of $\mathrm{O}_{2}$ to $\mathrm{H}_{2} \mathrm{O}$ (see Supplementary Fig. 2) 46-48 and exhibited a suitable potential for the uptake of electrons from the $\mathrm{F}_{\mathrm{B}}{ }^{-}$site of PS1, as determined by cyclic voltammetry (Supplementary Fig. 3). The recorded photocurrent at the sample was of similar magnitude as the one obtained in the presence of $\mathrm{MV}^{2+}$, indicating an efficient electron transfer from photo- 
a

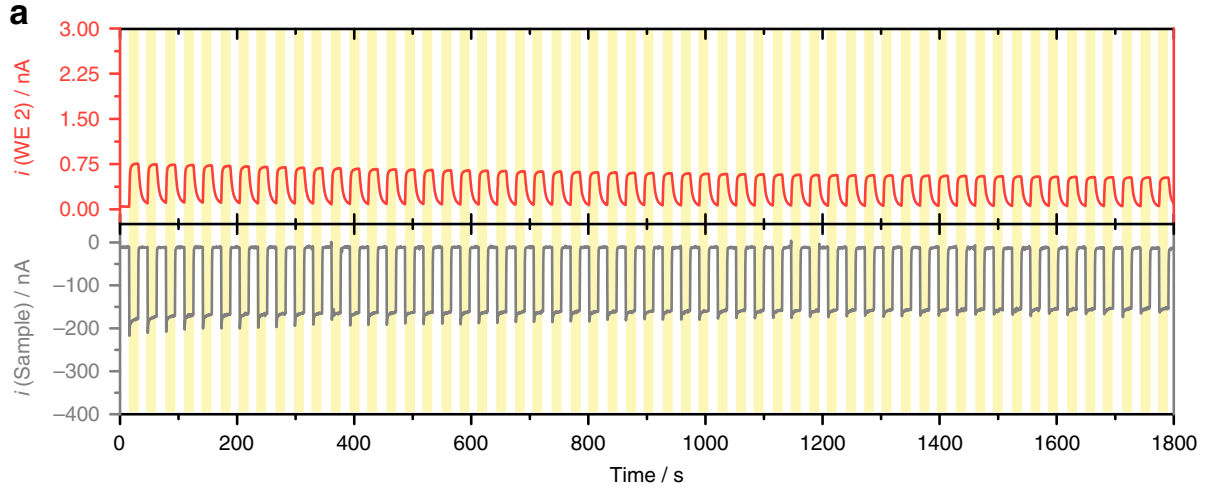

C

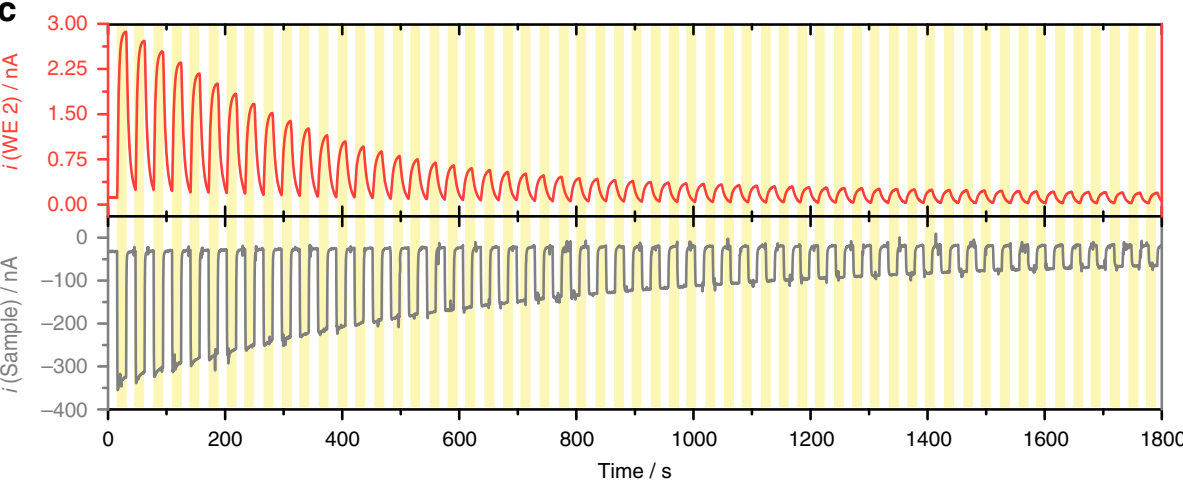

b

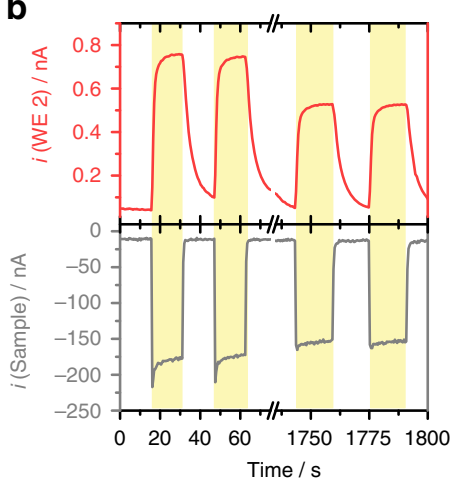

d

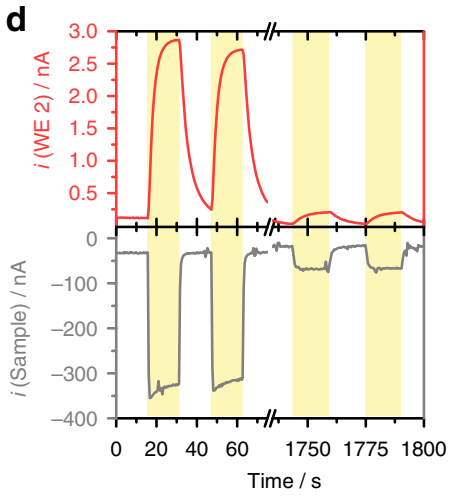

Fig. 4 Long-term stability of the photocurrent at varying $\mathrm{O}_{2}$ concentrations. Simultaneous photochronoamperometric responses and collection of $\mathrm{H}_{2} \mathrm{O}_{2}$ recorded at a PS1/Os-complex-modified redox polymer photocathode $\mathbf{a}, \mathbf{b}$ air-equilibrated solution and $\mathbf{c}, \mathbf{d} \mathrm{O}_{2}$-saturated solution. The sample was polarized at $0 \mathrm{mV}$, while the Pt disk microelectrode was polarized at $+600 \mathrm{mV}$ vs. $\mathrm{Ag} / \mathrm{AgCl} / 3 \mathrm{M} \mathrm{KCl}(\mathrm{WE} 2)$. Electrolyte: $3 \mathrm{mM} \mathrm{MV} 2+$ in $0.2 \mathrm{M}$ citratephosphate buffer, $\mathrm{pH}$ 7.0. Tip-to-sample distance: $10 \mu \mathrm{m}$. The sample was locally irradiated (white light, $280 \mathrm{~mW} \mathrm{~cm}^{-2}$ ) through the sheath of the positioned microelectrode for periods of $15 \mathrm{~s}$ as indicated by the yellow shaded regions in the graphs. A comparison of the initially recorded currents with the response obtained at the end of the experiment is given in graphs $\mathbf{b}, \mathbf{d}$ (note the different current scales for $\mathbf{b}$ in comparison with $\mathbf{a}$ )

excited PS1 to the molecular $\mathrm{Cu}$-complex in solution (Fig. 3c, gray trace). The concomitant decrease in the cathodic $\mathrm{O}_{2}$ reduction current under irradiation indicated the consumption of $\mathrm{O}_{2}$ (Fig. 3c, blue trace). Moreover, and as expected, the production of $\mathrm{H}_{2} \mathrm{O}_{2}$ was prevented when using CuTPA as an electron acceptor (Fig. 3c, red trace).

The small increase in the $\mathrm{H}_{2} \mathrm{O}_{2}$ oxidation current immediately after switching to irradiation may be attributed to the competing reduction of $\mathrm{O}_{2}$ by chlorophyll $a$ (Chla) (vide infra), leading to the potential formation of $\mathrm{H}_{2} \mathrm{O}_{2}$. This pathway was rapidly overtaken by the reduction of $\mathrm{O}_{2}$ and $\mathrm{H}_{2} \mathrm{O}_{2}$ by CuTPA, and hence no significant collection of $\mathrm{H}_{2} \mathrm{O}_{2}$ was further observed. The absence in $\mathrm{H}_{2} \mathrm{O}_{2}$ collection confirmed the previously obtained results and the capability of the analytical system for the determination of $\mathrm{H}_{2} \mathrm{O}_{2}$ as indicator for the presence of partially reduced oxygen species generated under irradiation.

Interestingly, the use of CuTPA as an electron acceptor was observed to lead to a remarkably quicker loss in activity of the PS1/Os-P photocathode as compared with $\mathrm{MV}^{2+}$ (Supplementary Fig. 4). The faster decay in photocurrent response in the case of CuTPA could be attributed to $\mathrm{Cu}$ plating at the stromal side of the photosystem. The unavoidable presence of free $\mathrm{Cu}^{2+}$ ions in the CuTPA solution entails the direct reduction and deposition of $\mathrm{Cu}^{0}$ at the $\mathrm{F}_{\mathrm{B}}^{-}$site, with the consequent blocking and loss in activity of the photosystem. These results prevent the use of $\mathrm{Cu}$ complexes for the development of efficient PS1-based photocathodes working under optimal conditions and with a minimized production of partially reduced oxygen species.
Evaluation of PS1/Os-P at varying $\mathrm{O}_{2}$ concentrations. The photocurrent and $\mathrm{H}_{2} \mathrm{O}_{2}$ production at the PS1/Os- $\mathrm{P}$ photocathode were further evaluated using $\mathrm{MV}^{2+}$ as the primary electron acceptor at two different $\mathrm{O}_{2}$ concentrations. The PS1/ redox polymer photocathode was evaluated in a sequence of successive light and dark periods (see Supplementary Fig. 5). The performance of the photocathode in air-equilibrated solutions was compared with the same experiment in an $\mathrm{O}_{2}$-saturated solution. The results are summarized in Fig. 4, where, for the sake of simplicity, the response of the $\mathrm{O}_{2}$ reduction at the Pt microdisk polarized at $-600 \mathrm{mV}$ (vs. $\mathrm{Ag} / \mathrm{AgCl} / 3 \mathrm{M} \mathrm{KCl}$ ) has been omitted. A relatively stable photocurrent was obtained for the photocathode working in air-equilibrated solution after $30 \mathrm{~min}$ (Fig. 4a). In contrast, an increased $\mathrm{O}_{2}$ concentration led to a faster loss of activity of the photocathode (Fig. 4c). Comparison of the initial photocurrents with those obtained at the end of the experiment highlights the major loss in activity for photocathodes working under $\mathrm{O}_{2}$-saturated solutions (Fig. 4b, d). While in airequilibrated solution the photocathode retained $87 \%$ of the initial response at the end of the experiment, the photocathode working in $\mathrm{O}_{2}$-saturated solution only preserved $17 \%$ of the initial photocurrent. The faster inactivation in the latter case was associated with a remarkably higher collection of $\mathrm{H}_{2} \mathrm{O}_{2}$ at the Pt microdisk electrode (cf. red traces in Fig. 4a, c).

The long-term stability of the PS1/Os-P film on Au electrodes was confirmed by recording successive cyclic voltammograms under dark conditions and comparing the redox signals of the immobilized polymer over time. The obtained results (Supplementary Fig. 6) exhibited a high stability of the polymer film over at least 100 cycles, ensuring a highly stable film for the duration of 
the experiments. Moreover, the stability of the redox polymer was also evaluated under conditions that would lead to the generation of ROS in the evaluated system. For this, cyclic voltammograms recorded under dark conditions were compared before and after a long-term uninterrupted photochronoamperometry experiment (Supplementary Fig. 7). The obtained results showed no decrease in the $\mathrm{Os}^{2+} / \mathrm{Os}^{3+}$ redox signal after $>40 \mathrm{~min}$ of the irradiation period. The slight increase in current observed in the voltammogram recorded after the long-term experiment could be ascribed to the swelling of the hydrogel due to solvation of the film. Although the film was exposed to the reactive species causing a loss in activity observed in the recorded photocurrent, the Oscomplex-modified redox polymer was sufficiently stable, confirming that the loss in activity of the photocathode was not attributed to a damage of the film or loss of material from the electrode surface but had to be related instead to an inactivation of the immobilized photosynthetic protein complexes.

Furthermore, to confirm that $\mathrm{O}_{2}$ was involved in the loss of activity over time of the evaluated photoelectrode through the generation of ROS under irradiation, a long-term photochronoamperometric study of the PS1/Os-P assembly was performed under nearly anaerobic conditions. In this case, 2-methyl-1,4naphthoquinone was used as an electron acceptor for the uptake of electrons from the $\mathrm{F}_{\mathrm{B}}$ site of PS1 in absence of $\mathrm{O}_{2}$ in solution. The obtained results (Supplementary Fig. 8) exhibited an increased stability of the analyzed photocathode in comparison with the system evaluated under aerobic conditions and using $\mathrm{MV}^{2+} / \mathrm{O}_{2}$ as an electron acceptor (cf. Supplementary Fig. 9 and Fig. 1). Under anaerobic conditions, the photocathode retained about $96 \%$ of the initial response after $30 \mathrm{~min}$ of the experiment, thus surpassing the previously observed retained activity after the same period of time for the photocathode evaluated under airequilibrated solutions. This fact clearly confirmed the implication of $\mathrm{O}_{2}$-derived reactive species that are responsible for the limited stability of the biophotocathode.

Incorporation of Cat and SOD. Following nature's scavenging mechanisms developed to overcome the deleterious effects of commonly generated ROS in living organisms, the enzymes SOD and Cat were selected for the suppression of harmful effects caused by oxygen radicals to the PS1/Os-complex-modified redox polymer photocathode. The enzymes were first co-immobilized together with PS1 within the redox polymer film. Different electrodes were fabricated including Cat, SOD, or a mixture of both enzymes together with the PS1/Os-P film deposited on $\mathrm{Au}$ electrode surfaces. The recorded current for the collection of $\mathrm{H}_{2} \mathrm{O}_{2}$ exhibited a significant decrease only in the presence of relatively large amounts of Cat in the polymer film (Supplementary Fig. 10). The fact that the photocurrent magnitude was similar for electrodes containing co-immobilized Cat or SOD confirmed that the same amount of PS1 was present in the mixed hydrogel film and that the photocathode response was not affected by the presence of Cat or SOD in the film. Further removal of produced $\mathrm{H}_{2} \mathrm{O}_{2}$ was not possible without affecting the magnitude of the obtained photocurrents. The effective removal of $\mathrm{H}_{2} \mathrm{O}_{2}$ by the disproportionation reaction catalyzed by Cat was evaluated by depositing a thin film of Cat or denatured Cat over the PS1/Os-P assembly. The obtained results (see Supplementary Fig. 11) showed that most of the generated $\mathrm{H}_{2} \mathrm{O}_{2}$ was consumed by the active immobilized enzyme before reaching the microelectrode. In contrast, when denatured Cat was used, $\mathrm{H}_{2} \mathrm{O}_{2}$ was able to diffuse through the film without being consumed, reaching the microelectrode where it was finally detected. Since the incorporation of a large amount of enzymes within the redox polymer disrupts the properties of the film in terms of electron transfer and diffusion rates (see Supplementary Fig. 12), unambiguous conclusions cannot be obtained about the long-term stability of the evaluated photocathode.

Further experiments with the enzymes Cat and SOD in solution indicated a clearly diminished collection of $\mathrm{H}_{2} \mathrm{O}_{2}$ as compared with the PS1-based photocathode in the absence of Cat or SOD (Supplementary Fig. 13). However, long-term measurements of the photocurrent for photocathodes working with Cat and SOD in solution revealed that even in the presence of scavenging enzymes the stability of the photocathode could not be increased. At the end of the experiment, the remaining photocurrent was about $62 \%$ with SOD, $82 \%$ with Cat, and $85 \%$ with the mixture of enzymes; compared to $87 \%$ for the PS1 photocathode in the absence of these enzymes (Supplementary Fig. 13). The obtained results suggested that the production of reactive species takes place within the protein complex or in close proximity to it. Hence, the generated species react rapidly before their harmful effect can be prevented by any scavenging mechanism that require the diffusion of large scavenger species.

Partially reduced oxygen species produced by Chla. In order to evaluate whether the generation of $\mathrm{H}_{2} \mathrm{O}_{2}$ as collected at the SPECM microelectrode tip was only associated with the main pathway of light-induced charge separation at PS1 (Fig. 1), a PS1/ Os-complex-modified redox polymer photocathode was analyzed using PS1 that had been previously inactivated by thermal treatment (see Methods section). The obtained results in the absence of any redox mediator in solution (Fig. 5a) revealed the generation of $\mathrm{H}_{2} \mathrm{O}_{2}$ even using the inactivated PS1 under irradiation (Fig. 5a, red trace) while the absence of any significant photocurrent confirmed the complete absence of iPS1 activity (Fig. 5a, gray trace). As described previously for PS2, chlorophyll molecules may be involved in the direct photo-induced reduction of $\mathrm{O}_{2}{ }^{42}$. After thermal treatment, the PS1 protein complex was not anymore in a fully functional state, and in consequence, the capability to perform light-induced charge separation was suppressed. Under these conditions, the tridimensional structure of the complex was lost, leaving exposed chlorophyll molecules accessible for electron-transfer processes and enabling the direct reduction of $\mathrm{O}_{2}$ at the chlorophyll upon light absorption. This led to the generation of partially reduced oxygen species and was accompanied by the formation of $\mathrm{H}_{2} \mathrm{O}_{2}$ as detected at the SPECM tip. Further studies were performed with respect to $\mathrm{O}_{2}$ reduction by chlorophyll pigments under irradiation. For this, a film of free Chla embedded in the same Os-complex-modified redox polymer and deposited on an $\mathrm{Au}$ electrode surface was analyzed. The results clearly showed the formation of $\mathrm{H}_{2} \mathrm{O}_{2}$ collected at the SPECM tip under irradiation of the sample (Fig. 5b), confirming that $\mathrm{Chl} a$ was capable for the reduction of $\mathrm{O}_{2}$ upon irradiation. Addition of $\mathrm{MV}^{2+}$ did not lead to significant differences, indicating that $\mathrm{MV}^{2+}$ was not involved in this reaction and that the excited chlorophyll directly reduced $\mathrm{O}_{2}$ in solution (notice the decreased cathodic current indicating $\mathrm{O}_{2}$ consumption under irradiation, Fig. 5b, blue trace).

\section{Discussion}

We have demonstrated the in situ detection of $\mathrm{H}_{2} \mathrm{O}_{2}$ and the associated $\mathrm{O}_{2}$ consumption at PS1/redox polymer-based photocathodes under light stress conditions. Performing the experiments over long periods of time while working with intermittent consecutive dark and light conditions were used to minimize variations in electron transfer and diffusion rates by potential local heating effects. Moreover, the use of intermittent illumination allows recording a clear baseline for photocurrent monitoring over extended periods of time, making long-term evaluation 

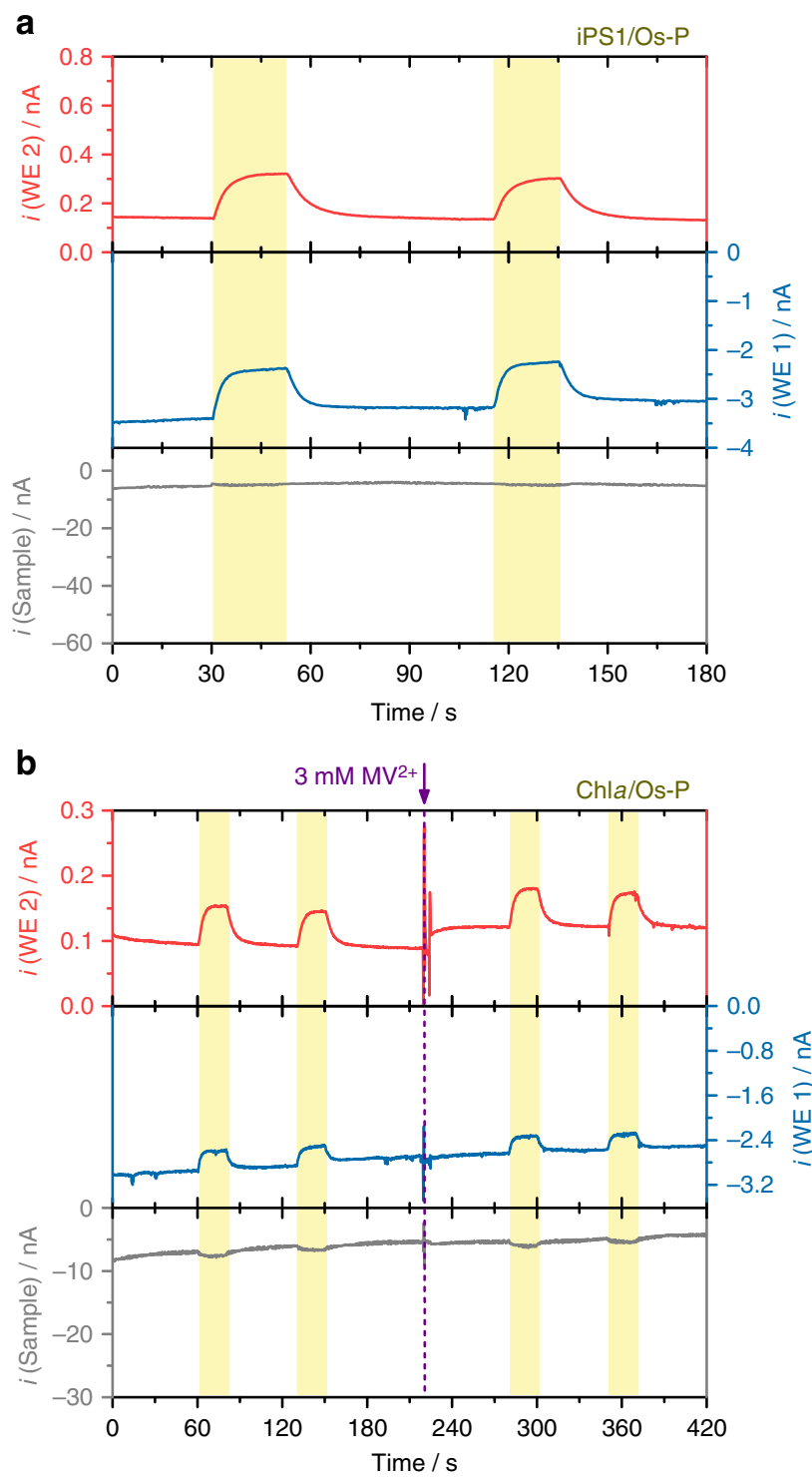

Fig. 5 Production of partially reduced oxygen species at inactivated PS1 and free Chla under irradiation. Simultaneous photochronoamperometric responses recorded for $\mathbf{a} \mathrm{iPS1} / \mathrm{Os}-\mathrm{P}$ and $\mathbf{b}$ free Chla/Os-P-modified electrodes. Electrolyte: $3 \mathrm{mM} \mathrm{MV}^{2+}$ in $0.2 \mathrm{M}$ citrate-phosphate buffer, $\mathrm{pH}$ 7.0 (for $\mathbf{b}$ addition of $\mathrm{MV}^{2+}$ at $220 \mathrm{~s}$ ). The sample was polarized at $0 \mathrm{mV}$, while the Pt disk microelectrodes were polarized at $-600 \mathrm{mV}$ (WE 1) and $+600 \mathrm{mV}$ (WE 2). All potentials vs. $\mathrm{Ag} / \mathrm{AgCl} / 3 \mathrm{M} \mathrm{KCl}$. Tip-to-sample distance: $10 \mu \mathrm{m}$. The sample was locally irradiated (white light, $280 \mathrm{~mW} \mathrm{~cm}$ ${ }^{-2}$ ) for periods of $20 \mathrm{~s}$, as indicated by the yellow shaded regions in the graphs

of the bioelectrodes under different conditions possible. PS1/Oscomplex-modified redox polymer photocathodes working under aerobic conditions generate partially reduced oxygen species, which are responsible for the degradation of the PS1 protein complex and a drop in activity of the photoelectrodes with time. Incorporation of Cat and SOD in the PS1/Os-P biodevice demonstrates that suppression of partially reduced oxygen species is difficult due to the high reactivity and short diffusion time of partially reduced oxygen species. We have additionally shown that the formation of these partially reduced reactive species under light is not only associated with the main electron-transfer pathway following charge separation by PS1 upon light absorption. $\mathrm{H}_{2} \mathrm{O}_{2}$ associated with $\mathrm{O}_{2}$ consumption could be also demonstrated for thermally inactivated PS1 complexes and free Chla, indicating the capability of $\mathrm{O}_{2}$ reduction by chlorophyll pigments. Our findings provide further understanding about electron-transfer pathways at PS1-modified electrode surfaces and highlight the limited applicability of PS1-based photocathodes working under aerobic conditions, where the unavoidable formation of ROS is responsible for an overall short long-term stability. Hence, the obtained results are strongly encouraging the design of PS1-based biophotocathodes operating under strictly anaerobic conditions.

\section{Methods}

Chemicals and materials. Poly(ethylene glycol)diglycidyl ether (PEGDGE, Polysciences), methyl viologen dichloride hydrate (Sigma-Aldrich, 98\%), and 2-methyl1,4-naphthoquinone (Alfa Aesar, 98\%) were of reagent grade and used without further purification. The redox polymer poly(1-vinylimidazole-co-allylamine)-Os $\left(2,2^{\prime} \text {-bipyridyl }\right)_{2} \mathrm{Cl}$ was synthesized and purified following previously reported procedures $^{13}, 49$. Briefly, a mixture of $4.6 \mathrm{mmol}$ allylamine and $30.6 \mathrm{mmol}$ vinylimidazole was copolymerized under argon atmosphere. The reaction was initiated by $1.5 \mathrm{mmol}$ of $2,2^{\prime}$-azobisisobutyronitrile and stirred for $2 \mathrm{~h}$ at $70^{\circ} \mathrm{C}$. The product was dissolved in ethanol, filtered, washed with acetone, and dried in vacuum. The copolymer backbone ( $84 \mathrm{mg} \mathrm{mL}^{-1}$ in ethanol) was then allowed to react with 0.18 mmol [Os(bipy) ${ }_{2} \mathrm{Cl}_{2}$ ] at $90^{\circ} \mathrm{C}$ under continuous stirring to give the final product. Cat from bovine liver (EC 1.11.1.6) and SOD from bovine erythrocytes (EC 1.15.1.1) were from Sigma-Aldrich. PS1 was isolated from cultures of the thermophilic cyanobacterium Thermosynechococcus elongatus BP-1 as described elsewhere ${ }^{45}$. In brief, the cells were grown in a $20 \mathrm{~L}$ foil fermenter at $45^{\circ} \mathrm{C}$ in BG11 medium supplemented with $5 \% \mathrm{CO}_{2}$ in air and light of increasing intensity (20 to $100 \mu \mathrm{mol}$ photons $\mathrm{m}^{-2} \mathrm{~s}^{-1}$ ). Cells were harvested at an $\mathrm{OD}_{680}$ of 3-3.5 and disrupted by Parr bomb. PS1 was isolated from thylakoid membranes by $\beta$-dodecyl maltoside treatment (1.2\%) followed by hydrophobic interaction chromatography and ion exchange chromatography. Purified PS1 showed an oxygen consumption activity of about $1100 \mu \mathrm{mol} \mathrm{O} \mathrm{h}^{-1} \mathrm{mg}_{\mathrm{Chl}}{ }^{-1}$. The inactivated photosystem (iPS1) was prepared by thermal treatment of $\mathrm{PS} 1^{50}$ using a silicone oil bath at $120^{\circ} \mathrm{C}$ for $60 \mathrm{~min}$. Chl $a$ was obtained from the purified PS1 protein sample by incubation for $24 \mathrm{~h}$ at room temperature (RT) in absolute EtOH (ThermoFisher Scientific), followed by centrifugation $(15,500 \times g$, RT, $10 \mathrm{~min})$. The supernatant was concentrated by centrifugal vacuum (Savant DNA 110 SpeedVac, ThermoFisher Scientific). All solutions were prepared with deionized water $(\rho=18 \mathrm{M} \Omega \mathrm{cm})$.

Electrode modification. Gold disk electrodes $(2 \mathrm{~mm} \emptyset, \mathrm{BASi})$ were cleaned prior to modification by polishing with diamond suspension (LECO) of decreasing grain sizes $(0.3 \mu \mathrm{m}, 0.1 \mu \mathrm{m}, 0.05 \mu \mathrm{m})$ and then sonicated successively in absolute ethanol and water. The gold electrodes were then electrochemically cleaned by cyclic voltammetry, recording 20 scans from -0.1 to $1.6 \mathrm{~V}$ (vs. $\mathrm{Ag} / \mathrm{AgCl} / 3 \mathrm{M} \mathrm{KCl}$ ) in $0.5 \mathrm{M}$ $\mathrm{H}_{2} \mathrm{SO}_{4}$ at $100 \mathrm{mV} \mathrm{s}^{-1}$. The electrode surface was modified with $2.5 \mu \mathrm{L}$ of a mixture of the redox polymer $\left(5 \mu \mathrm{g} \mu \mathrm{L}^{-1}\right)$, PEGDGE $\left(0.02 \mu \mathrm{g} \mu \mathrm{L}^{-1}\right)$, and the isolated PS1 (1 $\mu \mathrm{g} \mu \mathrm{L}^{-1}$ ) or free Chla (amount normalized by the chlorophyll content of PS1). PS1, iPS1, and Chla samples were incubated overnight in the dark at $4{ }^{\circ} \mathrm{C}$. Before measurement, the modified electrodes were incubated for $30 \mathrm{~min}$ in $50 \mathrm{mM}$ Tris$\mathrm{HCl}$ buffer solution of $\mathrm{pH} 9$ (containing $100 \mathrm{mM} \mathrm{KCl}, 10 \mathrm{mM} \mathrm{MgCl}_{2}$, and $10 \mathrm{mM}$ $\mathrm{CaCl}_{2}$ ) to induce polymer collapse and crosslinking ${ }^{18}$.

For the evaluation of films including Cat and SOD, Au-coated Si wafers were used as sample electrodes. $\mathrm{Si}(100)$ wafers (Wacker) were coated by vapor deposition in a metal vaporization setup (Leybold Univex 300) with a $1000 \AA$ A layer of gold over a $50 \AA$ adhesion layer of titanium. The Au wafers were cleaned with Piranha solution and then rinsed with distilled water before modification. The substrates were modified with $4 \mu \mathrm{L}$ of a mixture of the redox polymer $\left(5 \mu g \mu \mathrm{L}^{-1}\right)$, PEGDGE $\left(0.02 \mu \mathrm{g} \mu \mathrm{L}^{-1}\right)$, and the isolated PS1 $\left(1 \mu \mathrm{g} \mu \mathrm{L}^{-1}\right)$. Immediately after, an aliquot of Cat $\left(5 \mu \mathrm{g} \mu \mathrm{L}^{-1}\right)$ and/or SOD $\left(5 \mu \mathrm{g} \mu \mathrm{L}^{-1}\right)$ solution was dropped on the modified electrode, gently mixed, and incubated overnight to achieve the combined film.

Synthesis of CuTPA. CuTPA $\left(\mathrm{C}_{18} \mathrm{H}_{18} \mathrm{CuN}_{6} \mathrm{O}_{6}\right.$, Supplementary Fig. 2, molecular weight: $477.92 \mathrm{~g} \mathrm{~mol}^{-1}$ ) was synthesized as follows. Tris(2-pyridylmethyl)amine (Sigma-Aldrich, $62.4 \mathrm{mg} ; 0.2 \mathrm{mmol}$ ) was dissolved in absolute EtOH $(11 \mathrm{~mL}) . \mathrm{Cu}$ $\left(\mathrm{NO}_{3}\right)_{2} \cdot 3 \mathrm{H}_{2} \mathrm{O}(25.4 \mathrm{mg} ; 0.1 \mathrm{mmol}, 0.5$ eq. $)$ was added and the mixture was stirred at reflux temperature for $30 \mathrm{~min}$. EtOH was later removed by rotary evaporation. The crude product was washed with diethyl ether $(3 \times 3 \mathrm{~mL})$ and dried under vacuum offering the final product CuTPA in quantitative yield.

Characterization of electrochemical probes. Dual platinum microdisk electrodes were used for the simultaneous collection of $\mathrm{O}_{2}$ and $\mathrm{H}_{2} \mathrm{O}_{2}$ as well as for the localized irradiation of the investigated sample. The electrodes consisted of two platinum wires $(25 \mu \mathrm{m} \varnothing$, Goodfellow) sealed in a theta-type borosilicate glass capillary (Supplementary Fig. 1a). Cyclic voltammetry was used to investigate the electrochemical behavior of the dual electrode tips and to determine the surface 
area of the Pt microdisk electrodes (Supplementary Fig. 1b). The surface area was $(5.2 \pm 0.8) \times 10^{-6} \mathrm{~cm}^{2}$. Electrochemical crosstalk between the micro-electrodes originating from the overlap of the steady-state diffusion profiles formed at the two microdisk electrodes was evaluated by performing generation-collection experiments. For this, one of the disks was swept in a conventional cyclic voltammetric experiment, while the other disk was held at a potential sufficiently high to achieve steady-state oxidation of the reduced species generated at the other disk (Supplementary Fig. 1c,d). The fabricated electrodes exhibited different distances between the two microdisk surfaces (Supplementary Fig. 1a). Electrodes with a minimum separation of $60 \mu \mathrm{m}$ were selected, corresponding to a crosstalk of $<5 \%$ and ensuring minimal interference between the measured currents at both microdisk electrodes.

Photochronoamperometric measurements. SPECM measurements were performed using the modified gold electrode as sample, the dual Pt microdisk electrode as tip, an $\mathrm{Ag} / \mathrm{AgCl} / 3 \mathrm{M} \mathrm{KCl}$ reference electrode, and a Pt cylindrical mesh as counter electrode. The SPECM setup was previously described ${ }^{42}$ and consisted of step-motor-driven micrometer screws (Owis) and piezoelectric positioners (NanoCube, Physik Instrumente) for accurate positioning of the tip electrode in $x$ $y-z$ directions, a bipotentiostat (PGU-BI 100, IPS-Jaissle), and an in-house written control software. The main channel of the bipotentiostat was connected to the sample electrode while the second channel was connected to one of the Pt microdisk electrodes (Tip WE 1). A coupled Petit Ampère potentiostat (BASi) was used for the third channel and connected to the other Pt microdisk electrode (Tip WE 2). For local illumination of the sample, a Hg-Xe lamp (LC8 type 03, Hamamatsu Photonics) was coupled with the top glass wall of the tip microelectrode by means of a light fiber (HITRONIC POF Simplex PE). The dual Pt microdisk electrode was used simultaneously as a probe for electrochemical interrogation of the sample as well as for a source for localized illumination. The samples were irradiated using white light (Supplementary Fig. 14) with an effective light intensity of $280 \mathrm{~mW} \mathrm{~cm}^{-2}$ reaching the sample surface.

Photochronoamperometric measurements were performed with the tip positioned at a constant distance of $10 \mu \mathrm{m}$ above the surface of the interrogated sample in a stationary configuration. The tip was precisely positioned above the sample by recording approach curves in buffer solution keeping the sample unbiased and the tip microelectrode polarized at $-600 \mathrm{mV}$, a potential sufficient for the steady-state reduction of $\mathrm{O}_{2}$ in solution. Simultaneous collection of $\mathrm{O}_{2}$ and $\mathrm{H}_{2} \mathrm{O}_{2}$ was performed by polarizing one of the Pt microdisk electrodes at $-600 \mathrm{mV}$, whereas the other was held at $+600 \mathrm{mV}$. The sample potential was kept constant at an applied potential of $0 \mathrm{mV}$. All indicated potentials are vs. $\mathrm{Ag} / \mathrm{AgCl} / 3 \mathrm{M} \mathrm{KCl}$.

All experiments were performed at a temperature of $(22 \pm 1)^{\circ} \mathrm{C}$.

Data availability. Data supporting the findings of this manuscript are available from the corresponding authors upon reasonable request.

Received: 20 December 2017 Accepted: 26 April 2018

Published online: 17 May 2018

\section{References}

1. Mershin, A. et al. Self-assembled photosystem-I biophotovoltaics on nanostructured $\mathrm{TiO}_{2}$ and $\mathrm{ZnO}$. Sci. Rep. 2, 234 (2012).

2. Yehezkeli, O., Tel-Vered, R., Michaeli, D., Nechushtai, R. \& Willner, I. Photosystem I (PSI)/Photosystem II (PSII)-based photo-bioelectrochemical cells revealing directional generation of photocurrents. Small 9, 2970-2978 (2013).

3. Nguyen, K. \& Bruce, B. D. Growing green electricity: progress and strategies for use of photosystem I for sustainable photovoltaic energy conversion. Biochim. Biophys. Acta 1837, 1553-1566 (2014).

4. Stieger, K. R., Feifel, S. C., Lokstein, H. \& Lisdat, F. Advanced unidirectional photocurrent generation via cytochrome $\mathrm{c}$ as reaction partner for directed assembly of photosystem I. Phys. Chem. Chem. Phys. 16, 15667-15674 (2014).

5. LeBlanc, G., Gizzie, E., Yang, S., Cliffel, D. E. \& Jennings, G. K. Photosystem I protein films at electrode surfaces for solar energy conversion. Langmuir 30, 10990-11001 (2014).

6. Feifel, S. C., Stieger, K. R., Lokstein, H., Lux, H. \& Lisdat, F. High photocurrent generation by photosystem I on artificial interfaces composed of $\pi$-systemmodified graphene. J. Mater. Chem. A 3, 12188-12196 (2015).

7. Shah, V. B. et al. Linker-free deposition and adhesion of photosystem I onto nanostructured $\mathrm{TiO}_{2}$ for biohybrid photoelectrochemical cells. Langmuir 31, 1675-1682 (2015).

8. Stieger, K. R. et al. Engineering of supramolecular photoactive protein architectures: the defined co-assembly of photosystem I and cytochrome c using a nanoscaled DNA-matrix. Nanoscale 8, 10695-10705 (2016).
9. Stieger, K. R. et al. Biohybrid architectures for efficient light-to-current conversion based on photosystem I within scalable 3D mesoporous electrodes. J. Mater. Chem. A 4, 17009-17017 (2016).

10. Efrati, A. et al. Assembly of photo-bioelectrochemical cells using photosystem I-functionalized electrodes. Nat. Energy 1, 15021 (2016).

11. Kato, M., Cardona, T., Rutherford, A. W. \& Reisner, E. Covalent immobilization of oriented photosystem II on a nanostructured electrode for solar water oxidation. J. Am. Chem. Soc. 135, 10610-10613 (2013).

12. Mersch, D. et al. Wiring of photosystem II to hydrogenase for photoelectrochemical water splitting. J. Am. Chem. Soc. 137, 8541-8549 (2015).

13. Sokol, K. P. et al. Rational wiring of photosystem II to hierarchical indium tin oxide electrodes using redox polymers. Energy Environ. Sci. 9, 3698-3709 (2016).

14. Li, G. et al. Interfacial assembly of photosystem II with conducting polymer films toward enhanced photo-bioelectrochemical cells. Adv. Mater. Interfaces 4, 1600619 (2017)

15. Miyachi, M. et al. Photocurrent generation of reconstituted photosystem II on a self-assembled gold film. Langmuir 33, 1351-1358 (2017).

16. Friebe, V. M. et al. On the mechanism of ubiquinone mediated photocurrent generation by a reaction center based photocathode. Biochim. Biophys. Acta 1857, 1925-1934 (2016)

17. Friebe, V. M. \& Frese, R. N. Photosynthetic reaction center-based biophotovoltaics. Curr. Opin. Electrochem. 5, 126-134 (2017).

18. Kothe, T. et al. Engineered electron-transfer chain in photosystem 1 based photocathodes outperforms electron-transfer rates in natural photosynthesis. Chem. Eur. J. 20, 11029-11034 (2014).

19. Plumeré, N. \& Nowaczyk, M. M. Biophotoelectrochemistry of photosynthetic proteins. Adv. Biochem. Eng. Biotechnol. 158, 111-136 (2016).

20. Karuppanapandian, T., Moon, J.-C., Kim, C., Manoharan, K. \& Kim, W. Reactive oxygen species in plants: their generation, signal transduction, and scavenging mechanisms. Aust. J. Crop Sci. 5, 709-725 (2011).

21. Hui, Y., Jie, W. \& Carpentier, R. Degradation of the photosystem I complex during photoinhibition. Photochem. Photobiol. 72, 508 (2000)

22. Jiao, S., Emmanuel, H. \& Guikema, J. A. High light stress inducing photoinhibition and protein degradation of photosystem I in Brassica rapa. Plant Sci. 167, 733-741 (2004).

23. Scheller, H. V. \& Haldrup, A. Photoinhibition of photosystem I. Planta 221, 5-8 (2005).

24. Murata, N., Takahashi, S., Nishiyama, Y. \& Allakhverdiev, S. I. Photoinhibition of photosystem II under environmental stress. Biochim. Biophys. Acta 1767, 414-421 (2007)

25. Pospísil, P. Production of reactive oxygen species by photosystem II. Biochim Biophys. Acta 1787, 1151-1160 (2009).

26. Vass, I. Molecular mechanisms of photodamage in the photosystem II complex. Biochim. Biophys. Acta 1817, 209-217 (2012).

27. Yao, D. C. I., Brune, D. C. \& Vermaas, W. F. J. Lifetimes of photosystem I and II proteins in the cyanobacterium Synechocystis sp. PCC 6803. FEBS Lett. 586, 169-173 (2012).

28. Alboresi, A., Ballottari, M., Hienerwadel, R., Giacometti, G. M. \& Morosinotto, T. Antenna complexes protect photosystem I from photoinhibition. $B M C$ Plant Biol. 9, 71 (2009).

29. Baker, D. R. et al. Comparative photoactivity and stability of isolated cyanobacterial monomeric and trimeric photosystem I. J. Phys. Chem. B 118, 2703-2711 (2014)

30. Sonoike, K. Photoinhibition of photosystem I. Physiol. Plant. 142, 56-64 (2011).

31. Sonoike, K. Degradation of psaB gene product, the reaction center subunit of photosystem I, is caused during photoinhibition of photosystem I. Possible involvement of active oxygen species. Plant Sci. 115, 157-164 (1996).

32. Krieger-Liszkay, A., Kos, P. B. \& Hideg, E. Superoxide anion radicals generated by methylviologen in photosystem I damage photosystem II Physiol. Plant. 142, 17-25 (2011).

33. Takagi, D., Takumi, S., Hashiguchi, M., Sejima, T. \& Miyake, C. Superoxide and singlet oxygen produced within the thylakoid membranes both cause photosystem I photoinhibition. Plant Physiol. 171, 1626-1634 (2016).

34. Gill, S. S. \& Tuteja, N. Reactive oxygen species and antioxidant machinery in abiotic stress tolerance in crop plants. Plant Physiol. Biochem. 48, 909-930 (2010).

35. Rutherford, A. W., Osyczka, A. \& Rappaport, F. Back-reactions, short-circuits, leaks and other energy wasteful reactions in biological electron transfer: redox tuning to survive life in $\mathrm{O}_{2}$. FEBS Lett. 586, 603-616 (2012).

36. Fridovich, I. \& Hassan, H. Paraquat and the exacerbation of oxygen toxicity. Trends Biochem. Sci. 4, 113-115 (1979).

37. Koppenol, W. H., Stanbury, D. M. \& Bounds, P. L. Electrode potentials of partially reduced oxygen species, from dioxygen to water. Free Radic. Biol. Med. 49, 317-322 (2010). 
38. Bird, C. L. \& Kuhn, A. T. Electrochemistry of the viologens. Chem. Soc. Rev. 10, 49 (1981).

39. Lin, Q., Li, Q., Batchelor-McAuley, C. \& Compton, R. G. Use of 'split waves' for the measurement of electrocatalytic kinetics: methyl viologen mediated oxygen reduction on a boron-doped diamond electrode. Phys. Chem. Chem. Phys. 15, 7760-7767 (2013).

40. Thorneley, R. N. A convenient electrochemical preparation of reduced methyl viologen and a kinetic study of the reaction with oxygen using an anaerobic stopped-flow apparatus. Biochim. Biophys. Acta 333, 487-496 (1974).

41. Nowaczyk, M. M. \& Plumeré, N. Photosynthesis: short circuit at the chlorophyll. Nat. Chem. Biol. 12, 990-991 (2016).

42. Zhang, J. Z. et al. Competing charge transfer pathways at the photosystem IIelectrode interface. Nat. Chem. Biol. 12, 1046-1052 (2016).

43. Conzuelo, F. et al. High-resolution analysis of photoanodes for water splitting by means of scanning photoelectrochemical microscopy. Anal. Chem. 89, 1222-1228 (2017).

44. Zhao, F. et al. Interrogation of a PS1-based photocathode by means of scanning photoelectrochemical microscopy. Small 13, 1604093 (2017).

45. Badura, A. et al. Photocurrent generation by photosystem 1 integrated in crosslinked redox hydrogels. Energy Environ. Sci. 4, 2435-2440 (2011).

46. Tahsini, L. et al. Electron-transfer reduction of dinuclear copper peroxo and bis-mu-oxo complexes leading to the catalytic four-electron reduction of dioxygen to water. Chem. Eur. J. 18, 1084-1093 (2012).

47. Kakuda, S., Peterson, R. L., Ohkubo, K., Karlin, K. D. \& Fukuzumi, S. Enhanced catalytic four-electron dioxygen $\left(\mathrm{O}_{2}\right)$ and two-electron hydrogen peroxide $\left(\mathrm{H}_{2} \mathrm{O}_{2}\right)$ reduction with a copper(II) complex possessing a pendant ligand pivalamido group. J. Am. Chem. Soc. 135, 6513-6522 (2013).

48. Asahi, M., Yamazaki, S.-i, Itoh, S. \& Ioroi, T. Electrochemical reduction of dioxygen by copper complexes with pyridylalkylamine ligands dissolved in aqueous buffer solution: the relationship between activity and redox potential. Dalton. Trans. 43, 10705-10709 (2014).

49. Badura, A. et al. Photo-induced electron transfer between photosystem 2 via cross-linked redox hydrogels. Electroanalysis 20, 1043-1047 (2008).

50. Shubin, V. V. et al. Thermostability of photosystem I trimers and monomers from the cyanobacterium Thermosynechococcus elongatus. Spectrochim. Acta A Mol. Biomol. Spectrosc. 179, 17-22 (2017).

\section{Acknowledgements}

This work was supported by the Cluster of Excellence RESOLV (EXC 1069) funded by the Deutsche Forschungsgemeinschaft (DFG) as well as the Deutsch-Israelische Projektkooperation (DIP) in the framework of the project "Nanoengineered Optobioelectronics with Biomaterials and Bioinspired Assemblies". The authors are grateful to
Dr. S. Alsaoub and Dr. A. Ruff for the synthesis of the redox polymer. F.Z. is grateful for the financial support by the China Scholarship Council (CSC). N.P., H.Z., and S.H. acknowledge funding by the European Research Council (ERC Starting Grant 715900).

\section{Author contributions}

F.C., N.P., and W.S. conceived the research. F.C. and F.Z. performed all experiments. S.H. synthesized the CuTPA complex. V.H., M.M.N., and M.R. provided the cyanobacterial PS1 and free Chla. H.Z. established quinone-based anaerobic photocurrent generation. F. C. wrote the manuscript. N.P. added to the discussion and contributed to the preparation of the manuscript. W.S. contributed to the preparation of the manuscript and supervised the work.

\section{Additional information}

Supplementary Information accompanies this paper at https://doi.org/10.1038/s41467018-04433-z.

Competing interests: The authors declare no competing interests.

Reprints and permission information is available online at http://npg.nature.com/ reprintsandpermissions/

Publisher's note: Springer Nature remains neutral with regard to jurisdictional claims in published maps and institutional affiliations.

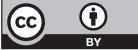

Open Access This article is licensed under a Creative Commons Attribution 4.0 International License, which permits use, sharing, adaptation, distribution and reproduction in any medium or format, as long as you give appropriate credit to the original author(s) and the source, provide a link to the Creative Commons license, and indicate if changes were made. The images or other third party material in this article are included in the article's Creative Commons license, unless indicated otherwise in a credit line to the material. If material is not included in the article's Creative Commons license and your intended use is not permitted by statutory regulation or exceeds the permitted use, you will need to obtain permission directly from the copyright holder. To view a copy of this license, visit http://creativecommons.org/ licenses/by/4.0/

(C) The Author(s) 2018 